مجلة العلوم الهندسية_العدد الثاني-2006

\title{
Proper Selection of Blasting Charges Location in Quarries and Open Cast Mines
}

\section{Dr.Mostafa Ahmed Ismail ${ }^{*}$}

\section{Abstract}

The aim of the present study is to assess the effect of the-zone of weakness on blasting efficiency and to determine the correct position of the explosive charge in relation to the suggested soft layers intercalated inclusions of soft materials avoid the escaping of blasting product (heat, pressure) in the contact layer between soft rock and hard rock (ore). Physical models having dimensions $(25 \times 25 \times 33 \mathrm{~cm})$ were made of cement and sand $(1: 3)$ to represent the strong rock deposits which are intercalated by inclusions or layer of soft material which represented by a mixture of cement and clay. The artificial rock models were tested with 5 gm, $10 \mathrm{gm}, 15 \mathrm{gm}, 20 \mathrm{gm}$, of gelatine dynamite with detonator No. 6.The charge of $10 \mathrm{gm}$ was more suitable with respect to the distance of throw which is more important for open cast mining with respect to the dimension of working area on a bench. It has found that, the plane of weakness has less effect when the charge is concentrated on the position after the inclusion of soft layer which gave pressure on soft layer and close the possibility of escaping products.

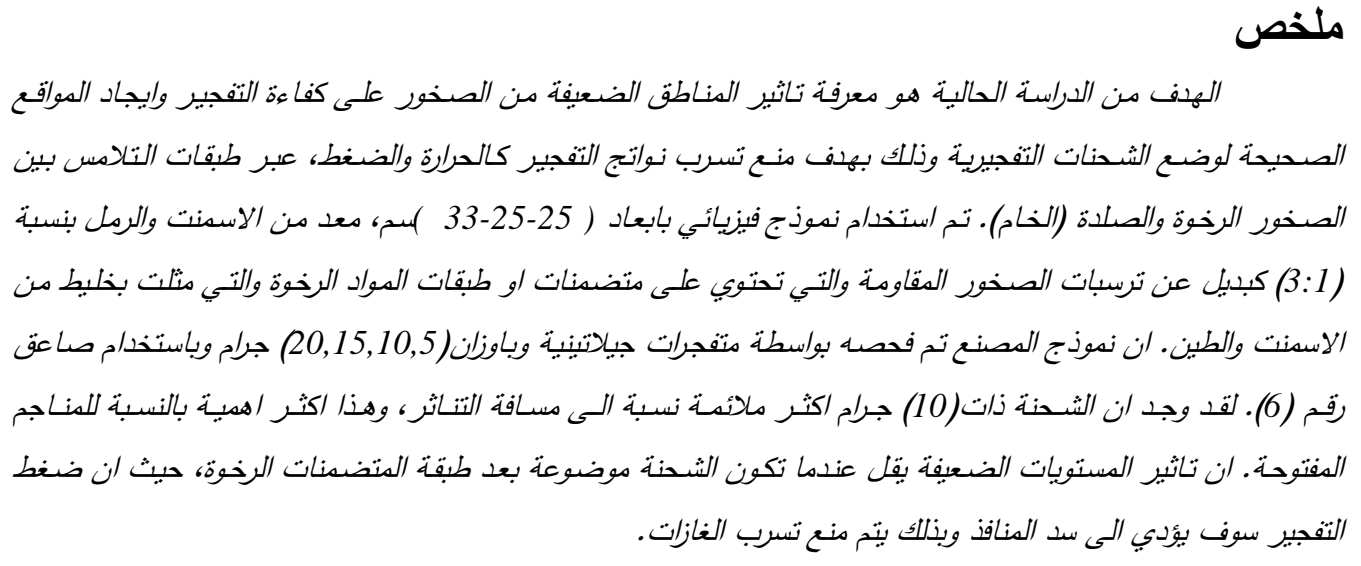

*Associate Prof. -Faculty of Petroleum and Mining Sues- Canal University 


\section{Introduction}

It is well known that blasting of an explosive charge will result in the formation of compressive waves which propagate through the surrounding media accompanied by very high pressure and temperature. These are due to the rapid change of the explosive charge from the solid state into very hot gasses having huge volume (1). The resulted gases from blasting are usually pressing, first, on the inner surface of the hole, however at the same time, they behave exactly as volcanoes which search for a weak place to escape through it. These places usually are the natural cracks or the inclusions formed from soft materials within rock bodies. Escaping of these gases from the cracks and faults will reduce remarkable the blasting efficiency. In other words, the amount of the large blocks of rocks in the fragmentation products will be great. (2). This, in turn, will require secondary blasting to be carried out on these blocks in order to ease shoveling and transportation operations. Secondary blasting, however, means that the quantity of explosives and their materials (i.e. detonators, safety fuse, etc...) will be increased making the blasting operations to be very expensive. Example, of such problems which have faced the blasting operations in Egypt, was quarrying of the basalt rock at Abu Zaabal. These deposits, usually having cracks of different sizes aperture and directions. The sizes of these cracks are enlarged as a result of weathering processes accomplished by the penetration of water within these rocks which enhanced by the variation in water temperature. The cracks are also filled with clay materials, which may draw from the surface soil covering these basaltic deposits. These filled cracks are, the weak places, which being faced during the rock blasting and through which the gases resulted from blasting would be escaped. The concluded result is the production of large blocks of rocks which are considered as a result of moving these naturally formed blocks by the blasting operation with only minor effect on the rock fragmentation. Fly rock is produced when explosive energy is excessive for the amount burden, stemming 
مجلة العلوم الهندسية_العدد الثاني-2006

is inadequate or the energy is too rapidly vented through a zone of weakness in the rock. When this happens, much of the explosive energy is used to throw rock, rather than to create fragmented rock and controlled displacement of the burden material geological condition, improper blasting design, or carelessness can cause dangerous fly rock pieces.

The aim of the present study is to assess the effect of the-zone of weakness on blasting efficiency and to determine the correct position of the explosive charge in relation to the suggested soft layers intercalated inclusions of soft materials avoid the escaping of blasting product (heat, pressure) in the contacting layer between soft rock and hard rock (ore). Physical models having dimensions $(25 \times 25 \times 33 \mathrm{~cm})$ were made of cement and sand $(1: 3)$ to represent the strong rock deposits which are intercalated by inclusions or layer of soft material which represented by a mixture of cement and clay. The artificial rock models were tested with $5 \mathrm{gm}, 10 \mathrm{gm}, 15 \mathrm{gm}, 20 \mathrm{gm}$, of dynamite with detonator No. 6 , the charge of $10 \mathrm{gm}$ was more suitable with respect to the distance of throw which is more important for open cast mining with respect to the dimension of working area on a bench. As shown in Fig. (1). The plane of weakness has less effect when the charge is concentrated on the position after the inclusion of soft layer which gave pressure on soft layer and close the possibility of escaping product. 

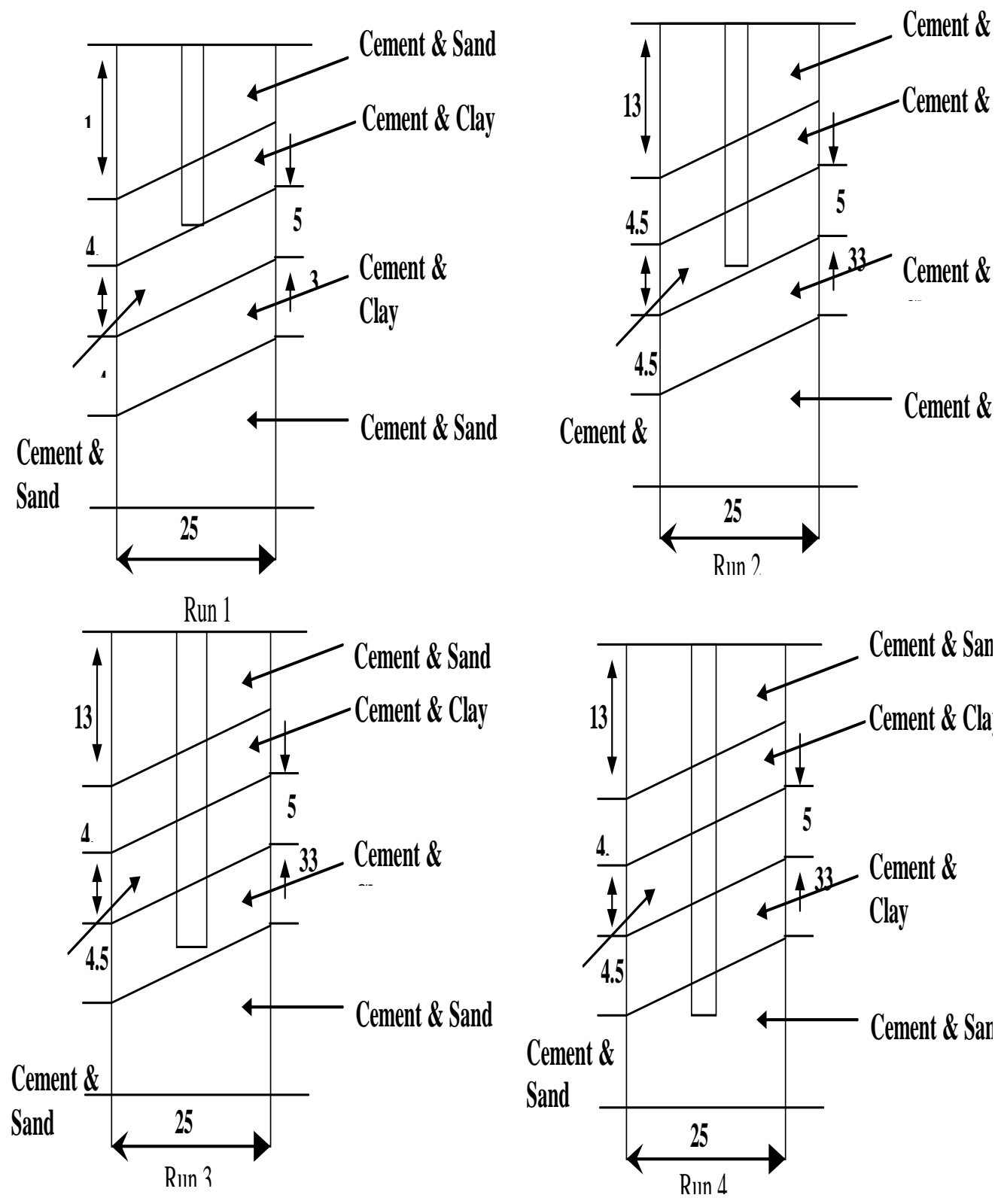

Fig. 1 Schematic diagram representing the model materials and depth of charged holes 
مجلة العلوم الهندسية_العدد الثاني-2006

\section{Experimental Work}

Physical models were made from cement and sand or clay as shown in Fig. (1) Those produced from cement-with sand represent the strong material to be blasted, however, cement -clay represent the soft, incompact weak filling inclusions which are usually present within the strong material deposit. These blocks were made to yield four groups (A, B, C and D).

In run 1 holes were made which having depth of $15 \mathrm{~cm}$. The bottoms are of the holes at the middle of the distance; between the two weak layers made of cement and clay. In the second run (B)- (run 2), the depths of the holes were increased to be $18 \mathrm{~cm}$ to make the bottom of the holes near the surface of the second weak layer and far from the other. In the third run (C)- (run 3 ) the drill holes depths were increased to $24 \mathrm{~cm}$ in order to locate the bottom of the holes beneath the lower layer and near to its lower surface. In the last run (D) which is the fourth one - (run 4), the drill holes were made to pass through the two weak layers and to reach the bottom of the model, i.e. the charge will be in the hard rocks which is beneath the soft rocks.

The amount of explosives required depend upon work to be done, the best blasting ratio for any particular quarry can be only found by trial for this purpose $5 \mathrm{gm}, 10 \mathrm{gm}, 15 \mathrm{gm}$ of dynamite is used, the amount of explosive per hole is calculated dividing the weight of rock by blasting ratio.

$$
\begin{aligned}
& \text { Charge/hole }=\frac{\text { B.S.D }}{\mathrm{Br}} \mathrm{lb} \\
& \text { Where } \mathrm{B}=\text { Burden } \mathrm{m} \\
& \mathrm{S}=\text { Spacing } \mathrm{m} \\
& \mathrm{D}=\text { Depth of hole } \mathrm{m} \\
& \text { Br}=\text { Explosive ratio } \mathrm{m}^{3} / \mathrm{lb}
\end{aligned}
$$

To blast a specified volume of material according to its characteristics, it was found that a $(10 \mathrm{gm})$ of gelatine dynamite is enough for the blasting 
purpose of this rock amount which should be charged in each hole to give suitable particle sizes compared to the size of the model (block).

Each group of blocks, in turn, was also grouped, one group was blasted on the surface and the other group was blasted after being inserted in a pit made in the ground.

\section{Results and Discussions}

The following table summarizes the percentage of the produced large particles of all four groups and the distances of flying rocks as well, However, plate (1) shows the size analysis of all groups.

\begin{tabular}{|c|c|c|}
\hline $\begin{array}{c}\text { Run } \\
\text { No. }\end{array}$ & Percentage of the largest particles \% & $\begin{array}{c}\text { Flying distances } \\
\mathrm{m}\end{array}$ \\
\hline 1 & 52 & 56 \\
\hline 2 & 50 & 41 \\
\hline 3 & 41 & 37 \\
\hline 4 & 70 & 25 \\
\hline
\end{tabular}


مجلة العلوم الهندسية_العدد الثاني-2006

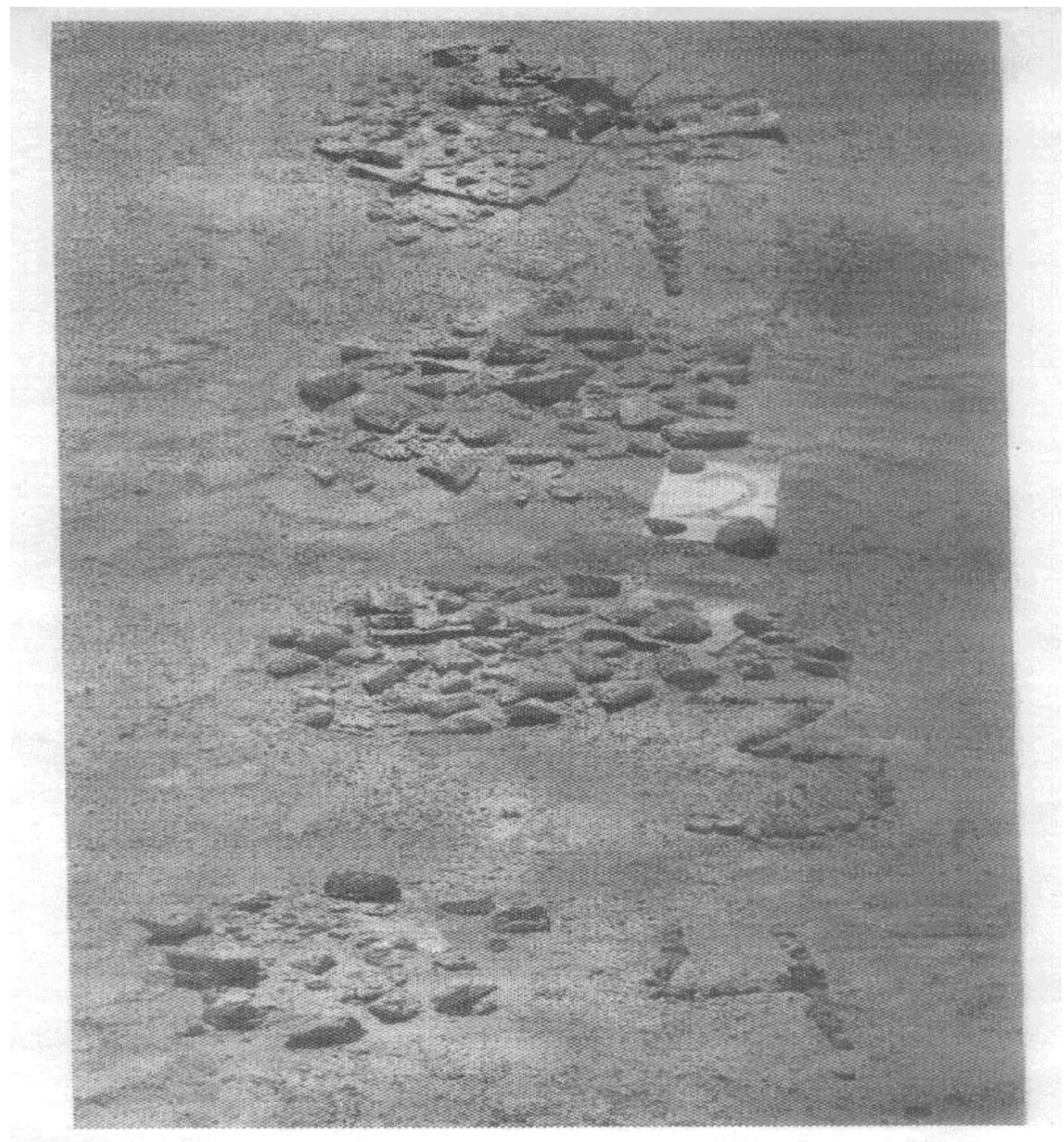

Plate (1)

From the analysis of the results, it is appeared that in the first series (see Figure (2) and Table (1)) of the groups, large fragments of the rocks are 
produced at the bottoms of the holes. This could be attributed to great quantity of the yielded gases at the bottom was escaped through the layer of clayey material layer due to occurrence of the discontinuity planes between the layers. This has led to concentrate the propagation of the blasting waves only on the top of the charged holes. The fly rock lumps have reached to approximately sixty meters far from the blasting point.

However, it could be observed from the results of the second group (see Figure (3) and Table (1)) that both the quantity of large lumps and the distance of flying were decreased. The results of the third group (see Figure (4) and Table (1)) indicate that lowest amount of large particles and smallest flying distance is characterizing this group which in turn are considered as the most suitable results.

The result of forth group (see Figure (5) and Table (1)) give about $70 \%$ of lumps what means that high leakage of gases decreasing of the pressure due to the presence of charge near the bottom of block 1.0 near the free surface.

An explanation can be given that placing the explosive charge immediately underneath the incompact rock layer (i.e. layer material layer) has imposed high pressure on this layer from lower. This has led to close the cracks and as a consequence no part of the blasting gases was escaped from the blasting holes through the sides of these holes. Therefore, all yield gases from the blasting of the explosive charge were involved in the breaking up of the rock surrounding the hole. The fourth group results show that the greatest part of the rock fragments was the larger ones (about 70\% of the total blasted rock), however, the flying distance was very small (around 25 meters). This is due to the location of the charge in great depths beneath the incompact and weak layer has led to disintegrate this layer which in turn has led to enlarge the cracks 
مجلة العلوم الهندسية_العدد الثاني-2006

within it giving a great chance to the gases to escape through the layer and this males the blasting waves not to transfer from the zone of the incompact layer. This phenomenon is called the mechanical crushing of the rocks.

\section{Conclusion}

From the above results, it may be concluded that it is of a great necessity to identify the geological conditions of the deposits to be lasted especially, the structural features such as (fissures, joints and weakness planes which vary from point continuity, direction, aperture, filling, etc....), since weathering the surface rock layers gives usually more anisotropic at the top portion of the deposits than the deeper rock mass. Therefore mapping the fissure and joints are of great importance at the top portion of the deposits before drilling and blasting be made. In addition to determination of the physical and mechanical properties of the rock should be carried out. Hence according to the structure and requirements of the blasting, the explosive charge should be correctly located and distributed within the hole. The place of explosive charge in the third group, i.e. after the last layer of soft rock, gives the best fragmentation and low fly distance which affect on the productivity of excavating-loading equipment and best for working area on the bench.

\section{References}

[1] U. lanfors and Kihlstron, The modern technique of rock blasting 1962.

[2] Per-Andres, Persson, Roger Hofmberg, Jaimin Lee, Rock drilling and explosive engineering, 1994. 
[3] H.A Bilfin \& A.G. pasamhnetogla \& R.T. Orkanman. Effect of dominant discontinuity orientation on blasting. Mine planing equipment.

[4] Flentcher-Larry \& Andrea-Dennis, Control of fly rock in blasting, Journal of explosive engineering v. 71990.

[5] Incas-Roger; Nies-pale, Improving Fragmentation and ore displacement control at Homestake Micklaughlin mine lower lake California. Proceeding of the $16^{\text {th }}$ Annual Conference on explosive and Blasting technique orlando USA 1990.

[6] Geddes. Swedich drilling and Blasting Practive. 1986.

[7] Hill- R.W, Drilling and Blasting Practices., Proceedings, Annual Metiry AIME. 1991. 
مجلة العلوم الهندسية_العدد الثناني-2006

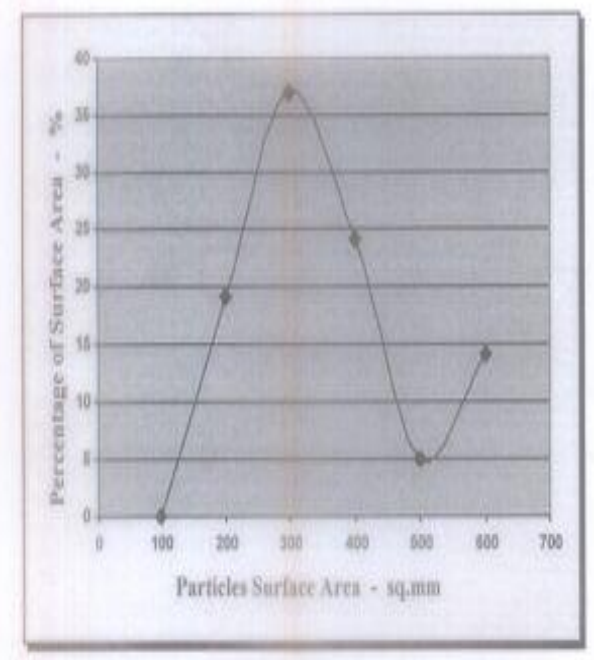

Fig, 1:

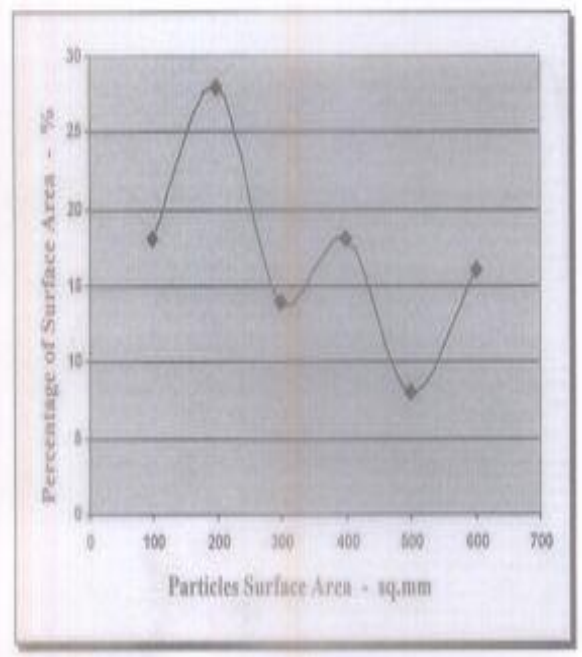

Fig, 3:

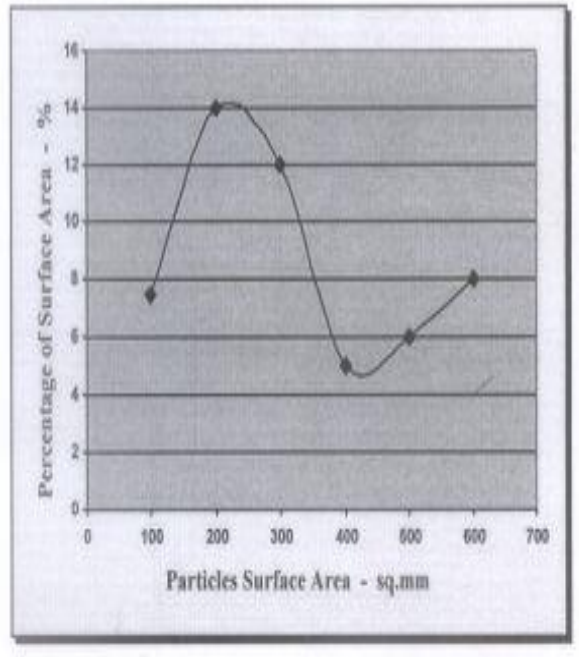

Fig. 2:

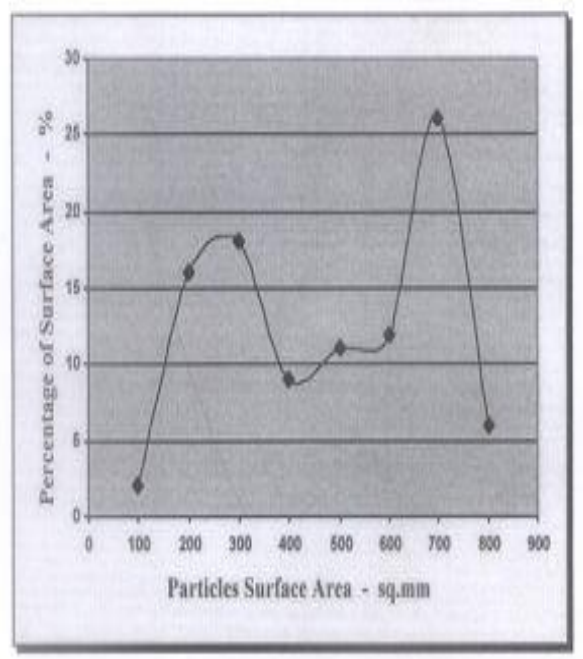

Fig. 4: 